\title{
Effects of Free Fatty Acid on Polymerization of Islet Amyloid Polypeptide (IAPP) In Vitro and on Amyloid Fibril Formation in Cultivated Isolated Islets of Transgenic Mice Overexpressing Human IAPP
}

\author{
Zhi Ma and Gunilla T. Westermark \\ Division of Cell Biology, Linköping University, Linköping, Sweden \\ Accepted October 14, 2002
}

\begin{abstract}
Background: Islet amyloid polypeptide (IAPP) is deposited as amyloid in the islets of Langerhans in type $2 \mathrm{di}-$ abetes. The mechanism behind the formation of the cytotoxic fibrils is unknown. Islet amyloid develops in a mouse IAPP null mouse strain that expresses human IAPP (+hIAPP/-mIAPP) after 9 months on a high-fat diet. Herein we investigate the effect that individual free fatty acids (FFAs) exert on formation of amyloid-like fibrils from synthetic IAPP and the effects of FFAs on IAPP polymerization in +hIAPP/-mIAPP islets cultivated in vitro. Materials and Methods: In the study myristic acid, palmitic acid, stearic acid, oleic acid, and linoleic acid were used together with albumin. Thioflavin $\mathrm{T}(\mathrm{Th} \mathrm{T})$ assay was used for quantification of amyloid-like fibrils. Islets were isolated from the +hIAPP/-mIAPP transgenic strain and cultured in the presence of the FFAs for 2 days. Immunoelectron microscopy was used for evaluation.
\end{abstract}

Results: The Th T assay showed that all studied FFAs potentiated fibril formation but that myristic acid revealed the highest capacity. In some cells from cultured islets, intragranular aggregates were present. These aggregates had a filamentous appearance and labeled with antibodies against IAPP. In some cells cultured in the presence of linoleic acid, large amounts of intracellular amyloid were present. Earlier, this has not been observed after such a short incubation period.

Conclusions: Our studies suggest that FFAs can potentiate amyloid formation in vitro, probably without being integrated in the fibril. Cultivation of +hIAPP/-mIAPP transgenic mouse islets with FFAs results in altered morphology of the secretory granules with appearance of IAPPimmunoreactive fibrillar material. We suggest that such fibrillar material may seed extracellular amyloid formation after exocytosis.

\section{Introduction}

The pathogenesis of type 2 diabetes mellitus is not fully understood. Peripheral mechanisms resulting in insulin resistance as well as $\beta$ cell abnormalities are known to be involved. The most constant structural islet abnormality in type 2 diabetes mellitus is deposition of islet amyloid $(1,2)$. In advanced lesions the whole islet may be converted into amyloid, thus leading to decreased numbers of $\beta$ cells. Islet amyloid deposits consist predominantly of fibrils formed by polymerization of a 37 amino acid polypeptide identified as islet amyloid polypeptide (IAPP; amylin) and IAPP is in human and other mammals mainly produced by $\beta$ cells (3-5). IAPP is stored and released together with insulin at exocytosis $(6,7)$. The physiologic function of IAPP is not fully clarified, but recent result point towards a modulating effect on insulin secretion through an autocrine or paracrine mechanism (8).

The homogeneous-appearing amyloid substance observed with light microscopy consists of proteins arranged in characteristic $\beta$-sheet fibrils, which

Address correspondence and reprint requests to:

Gunilla T. Westermark, Division of Cell Biology, Linköping University, SE-58185 Linköping, Sweden. Phone: +46-13-223906; fax: +46-13-224149; e-mail: gunwe@ibk.liu.se manifest specific staining properties with the dye Congo red. IAPP-derived amyloid is restricted to a few species and is mainly found in human $(>95 \%)$, adult cats, and non-human primates in conjunction with type 2 diabetes (9). Islet amyloid does not occur in the mouse or rat. These species differences are due to amino acid sequence variations in the respective IAPP molecules (10). Therefore, amyloid formation can not be studied in wild-type mice. Instead, for this purpose, transgenic mouse strains expressing the gene for human IAPP (hIAPP) have been established (11-14).

The mode of induction of amyloid formation is not known, but factors such as oversecretion of IAPP might be of importance, given the high frequency of IAPP-derived amyloid deposits in insulinomas in which both insulin and IAPP may be overproduced. However, the low incidence of islet amyloid in hIAPP transgenic mice overexpressing IAPP points to the probability that additional factors are involved in the fibrillogenesis of IAPP $(15,16)$.

Westernization has been associated with increased intake of dietary fat and has been suggested to be an important risk factor for the development of type 2 diabetes, especially in migrant populations (17). Free fatty acids (FFAs) are an important physiologic fuel for islets, and they also act as supplemental 
nutrient secretagogues to potentiate insulin release acutely in the presence of glucose. Some studies have shown that increased fat intake can impair islet $\beta$ cell function, in addition to producing obesity and insulin resistance. In mice studied while their dietary fat consumption was increased, $\beta$ cell function was reduced as measured as decreased insulin release from perifused isolated islets (18). In contrast to the potentiation of FFAs on glucose-induced insulin secretion, FFAs inhibit glucose-induced proinsulin biosynthesis (19). On the other hand, when isolated islets are used, $24 \mathrm{hr}$ of exposure to fatty acids reduces both insulin biosynthesis and release while removal of the fatty acids from the medium results in the reversal of this suppression (20). Chronic exposure to FFAs could severely deplete the internal insulin stores because there is apparently no biosynthetic backup to compensate for FFA-induced insulin hypersecretion. Recently, one study showed that fatty acids could reduce posttranslational processing of the endoproteases $\mathrm{PC} 1 / 3$ and PC2, which are responsible for processing of proinsulin to insulin and of pro-IAPP to IAPP (21).

In the hIAPP transgenic mouse strain that our group has established, amyloid does not appear spontaneously. Instead, islet amyloid appears in these mice after long-term, high-fat dietary intake (22). This phenomenon was originally reported to occur in another transgenic mouse strain expressing hIAPP (15). The association between high fat intake and islet amyloidosis has not been explained but, interestingly, when normal mice were fed a high-fat diet during a 6-month period, the plasma levels of IAPP and insulin increased (23). Notable was the finding that the IAPP plasma concentration increased 4.5 times while the plasma insulin concentration only increased 1.3 times. This resulted in a shift of the IAPP to insulin molar ratio from $6.3 \%$ in the control group to $20.5 \%$ in the experimental group. This may indicate that it is not the increased IAPP concentration per se that is of most importance for amyloid induction, but rather the relationship between the concentrations of IAPP and insulin. Human IAPP has an unusual tendency to form amyloid-like fibrils in vitro and we have postulated that factors inhibiting fibril formation must be present normally in $\beta$-cells. In fact, insulin is in vitro a strong inhibitor of IAPP fibril formation (24-26). There may also exist components that promote IAPP fibril formation. Interestingly, it has been reported that FFAs stimulate the polymerization of tau and amyloid $\beta$-peptides in vitro (27). A 20 - to 30 -fold increase in protein tau polymer formation was observed when $50 \mu \mathrm{M}$ arachidonic, palmitoleic, or linoleic acid was used.

In the present study we show, with the use of different in vitro systems based both on synthetic peptides and on in vitro cultivated pancreatic islets, that FFAs are potent enhancers of islet amyloid formation.

\section{Materials and Methods}

\section{Free Fatty Acids}

The Na salts of myristic acid, oleic acid, linoleic acid, palmitic acid, stearic acid, and thioflavin $\mathrm{T}(\mathrm{Th} \mathrm{T})$ were obtained from Sigma (St. Louis, MO, USA). The synthetic full-length wild-type hIAPP (IAPP 1-37) was synthesized at Keck Center, Yale University (New Haven, CT, USA). IAPP was C-terminally amidated and cyclized. Fatty acid ultra-free serum albumin and collagenase $\mathrm{P}$ were purchased from Boehringer Mannheim Biochemicals (Mannheim, Germany).

\section{Effects of FFAs on IAPP Fibril Formation In Vitro}

Synthetic IAPP was dissolved in dimethylsulfoxide at $2.5 \mathrm{mM}$. FFAs were dissolved in ethyl alcohol at three different concentrations: $5 \mathrm{mM}, 500 \mu \mathrm{M}$, and $5 \mu \mathrm{M}$. To test tubes containing $44 \mu \mathrm{l}$ distilled water were added $5 \mu \mathrm{l}$ of a FFA solution and thereafter $1 \mu \mathrm{l}$ of the IAPP solution. To control samples, ethanol without FFA was added. The concentration of DMSO and ethanol was $4 \%$ and $10 \%$ in all tubes, respectively. From each of the tubes $1 \mu \mathrm{l}$ samples in triplicate were taken at $30 \mathrm{~min}, 1 \mathrm{hr}, 6 \mathrm{hr}, 12 \mathrm{hr}$, and $24 \mathrm{hr}$. The samples were put on glass slides, air-dried, stained with alkaline Congo red (28), and examined in a polarization microscope for green birefringence, typical of amyloid. At $24 \mathrm{hr}, 1 \mathrm{ml}$ distilled water was added and the tubes were then centrifuged at $17,600 \times \mathrm{g}$ (Sigma centrifuge) for $1 \mathrm{hr}$. Of the supernatant, $0.9 \mathrm{ml}$ was removed, the pelleted material resuspended, and aliquots were put on Formvar-coated copper grids, negatively contrasted with $2 \%$ uranyl acetate in $50 \%$ ethanol, and examined in a Jeol 1200 electron microscope at $80 \mathrm{kV}$.

\section{Thioflavine T Fluorometric Assay}

Th $\mathrm{T}$ is a substance that binds specifically to amyloid fibrils. Binding of the dye to amyloid fibrils in suspension generates a fluorescent signal that can be measured at excitation $442 \mathrm{~nm}$ and emission $485 \mathrm{~nm}$ in a Fluoroskan (Ascent Fluorometer, Labsystems, Helsinki, Finland). In this fluorometric assay the amyloid fibril assembly process can be monitored, and the technique is useful for studies of the effects of various substances on fibril formation $(29,30)$.

The experiments were performed in a 100- $\mu$ l assay volume containing $4 \mu \mathrm{M}$ IAPP, 50 or $125 \mu \mathrm{M}$ FFAs, $25 \mu \mathrm{M}$ albumin (FFA:albumin $2: 1$ or $5: 1$ ), $50 \mathrm{mM}$ glycine, $25 \mathrm{mM}$ sodium phosphate buffer, $\mathrm{pH} 7.4$, and $10 \mu \mathrm{M}$ Th T. IAPP was dissolved in DMSO and the final concentration in the assay was $4 \%$ DMSO. The FFA and albumin was mixed 30 min prior to addition of the other components. In one set of experiments the albumin was abolished from the study. Fluorescence was measured every 15 min over a 24 -hr time period in 96-well black Cliniplates (Labsystems). All plastic ware used in the fluorescence assay was treated with Sigmacote (Sigma). In every experiment each mixture was studied in eight identical samples. The results are 
presented as mean values of eight samples. The experiments were repeated at least three times.

\section{Amyloid Formation in Isolated Islets}

Islet Isolation Pancreatic islets were isolated from 16 female + hIAPP/-mIAPP mice, 3-6 months of age. This mouse strain expresses hIAPP but not mIAPP and has been established by step-wise breeding of transgenic mice carrying the human IAPP gene with IAPP null mutant (mIAPP-/-) mice (22). The pancreata were removed under sterile conditions and placed in Hank's balanced salt solution (HBSS) and finely minced. The small pieces of tissue were enzymatically digested by collagenase $P$ ( $1.5 \mathrm{mg} / \mathrm{pan}$ creas) in HBSS for $15 \mathrm{~min}$ at $37^{\circ} \mathrm{C}$. Islets were handpicked under the microscope. The isolated islets were cultured overnight in 24-well cell culture cluster (Costar, Cambridge, MA) containing RPMI 1640 medium supplemented with $10 \%(\mathrm{v} / \mathrm{v})$ fetal bovine serum (FBS), penicillin (100 units $/ \mathrm{ml}$ ), streptomycin $(0.1 \mathrm{mg} / \mathrm{ml})$, and $11.1 \mathrm{mM}$ glucose at $37^{\circ} \mathrm{C}$ in humidified air containing $5 \% \mathrm{CO}_{2}$.

During the experiments, the islets were cultured in $500 \mu \mathrm{l}$ RPMI-1640 containing $11.1 \mathrm{mM}$ glucose, $300 \mu \mathrm{M}$ of the studied FFA and $150 \mu \mathrm{M}$ fat-free albumin (FFA:albumin $2: 1$ ) at $37^{\circ} \mathrm{C}$ in a $5 \% \mathrm{CO}_{2}$ atmosphere for 2 days.

\section{Immune Electron Microscopy}

At the end of the culture period the islets were fixed in $2 \%$ paraformaldehyde and $0.25 \%$ glutaraldehyde in $0.1 \mathrm{M}$ sodium cacodylate buffer, $\mathrm{pH} 7.4$, containing $0.1 \mathrm{M}$ sucrose. After fixation, the cells were dehydrated in ethanol and embedded in Epon. Ultrathin sections of the islets were cut and mounted on nickel grids. Specimens were immunogold-labeled for IAPP using an antiserum (A110) against mouse/ratIAPP (diluted 1:50), which reacts equally well with hIAPP and mIAPP (31). Antibody binding sites were identified with swine anti-rabbit IgG conjugated 10 nm-gold particles (Biocell Laboratories, Cardiff, UK). Contrast of the sections was enhanced with uranyl acetate and lead citrate. The sections were studied in a JEOL 1200 electron microscope (JEOL, Tokyo, Japan).

\section{Results \\ In Vitro Fibril Formation}

We used three different methods to establish reliably the formation of amyloid-like fibrils in vitro and the effect of FFAs. For Congo red binding and electron microscopy, FFAs were tested without presence of albumin because albumin interfered with staining and negative contrasting. In the Congo red test, dependent on specific and ordered binding of dye molecules on the fibrils, green birefringence typical of amyloid was seen when $50 \mu \mathrm{M}$ IAPP had been incubated alone for $6 \mathrm{hr}$ (Table 1). When the same concentration of IAPP was co-incubated with
Table 1. Time (min) after which amyloid-like fibrils appeared, as revealed by Congo red staining, when IAPP $(50 \mu \mathrm{M})$ and three different concentrations of fatty acids were co-incubated

Concentration of Fatty Acid* ( $\mu \mathrm{M})$

\begin{tabular}{lcccc}
\cline { 2 - 5 } & $\mathbf{5 0 0}$ & $\mathbf{5 0}$ & $\mathbf{0 . 5}$ & $\mathbf{0}$ \\
\hline IAPP alone & - & - & - & 360 \\
Myristic acid + IAPP & 30 & 30 & 30 & \\
Oleic acid + IAPP & 30 & 30 & 60 & \\
Palmitic acid + IAPP & 30 & 30 & 30 & \\
Linoleic acid + IAPP & 30 & 30 & 360 & \\
Stearic acid + IAPP & 30 & 30 & 30 &
\end{tabular}

Results are from one out of three independent experiments, which all gave the same results.

$500 \mu \mathrm{M}$ or $50 \mu \mathrm{M}$ of any of the FFAs myristic, oleic, linoleic, palmitic or stearic acid, green birefringent material was detected much earlier (Table 1). Also at a concentration of $0.5 \mu \mathrm{M}$, all FFAs except linoleic acid enhanced formation of amyloid-like fibrils. FFAs alone did not bind Congo red and exhibited no green birefringence. Electron microscopy was performed on the samples after incubation for $24 \mathrm{hr}$. All samples contained long, slightly wavy amyloidlike fibrils and no difference in morphology between preparations was found (Fig. 1A, 1B).

\section{Kinetic Studies}

Fibril formation of IAPP and other amyloid fibril proteins such as $\mathrm{A} \beta$ occurs in vitro after a significant lag phase during which a nucleation process is believed to take place (32) and this phenomenon was seen also in this study. When FFAs were analyzed without the addition of IAPP there was no detectable fluorescence even after $24 \mathrm{hr}$. Presence of FFA bound to albumin strongly enhanced the $\mathrm{Th} T$ signal and the lag phase was considerably shortened (Fig. 2). The potencies of the different FFA varied, but they all enhanced the fibril formation both in time and in amount. Most dramatic effect was seen in the presence of $125 \mu \mathrm{M}$ myristic acid (FFA:albumin 5:1) where the fibril concentration increased 4-fold as measured by Th T fluorescence (Fig. 2). When IAPP was co-incubated with albumin alone, the amyloidlike fibril formation occurred slightly delayed and the Th T signal was slightly lower (data not shown). In another experiment, IAPP was incubated with FFAs unbound to albumin. When this protocol was used, a dramatic enhancing effect on the fibril formation occurred. There was no obvious lag phase and the $\mathrm{Th} \mathrm{T}$ fluorescence reached maximum within $1 \mathrm{hr}$ and was three to four times higher than the levels observed when albumin was present (data not shown). 


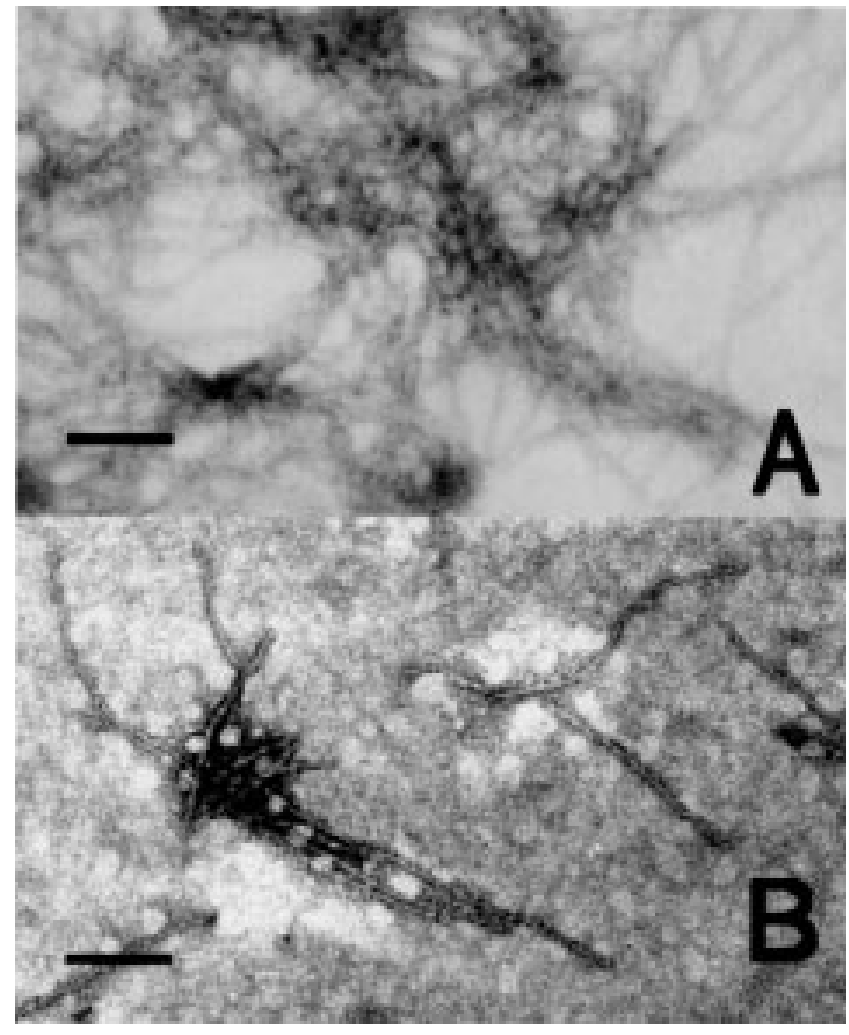

Fig. 1. (A) Amyloid-like fibrils formed from synthetic IAPP 1-37. (B) Fibrils formed from IAPP in the presence of $0.5 \mu \mathrm{M}$ myristic acid. Negatively contrasted with $2 \%$ uranyl acetate. $\mathrm{Bar}=50 \mathrm{~nm}$.

\section{Amyloid Formation in Cultured Isolated Islets}

Because amyloid fibril formation is a nucleationdependent process, the very initial fibril formation is important to study to understand the development of amyloid deposition. We have previously found that isolated +hIAPP/-mIAPP islets form IAPP-amyloid after incubation in vitro for 10-14 days (22). In the present study we chose a shorter incubation time to study possible effects of FFAs on the very first amyloid formation. The immunolabeling of the control tissue material incubated without addition of FFAs showed a specific reactivity of antibodies against IAPP within the secretory granules and this immunoreaction was often localized to the halo region (Fig. 3B). No abnormal structures were seen and there was no aberrant IAPP immunolabeling. In all islets incubated with FFAs, some $\beta$ cells had secretory granules that were characterized by the presence of abnormal flocculated and faintly fibrillar material that was distinctly IAPP immunoreactive. These IAPP-immunoreactive aggregates were located in the halo region of the secretory vesicles (Fig. 3C, 3D) and were not seen in islets incubated without FFAs. The most pronounced secretory vesicles alteration was observed in the islets incubated with myristic acid (Fig. 3C). In some cells incubated with linoleic acids, a large

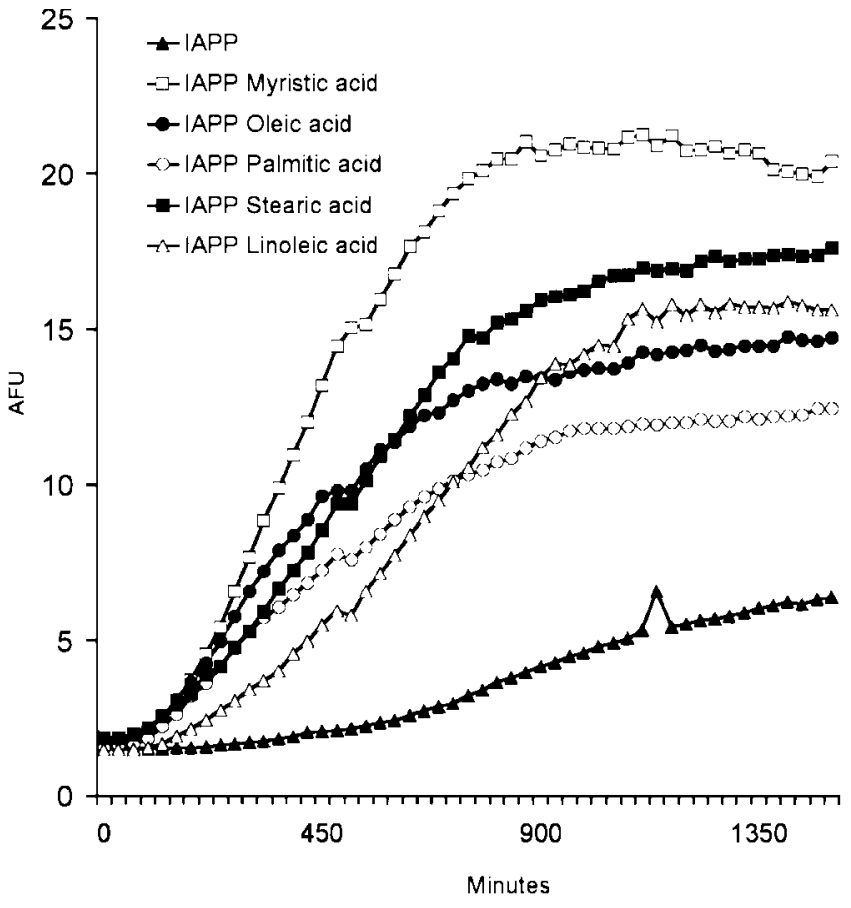

Fig. 2. Thioflavin $\mathbf{T}$ assay. Studies on IAPP fibril formation in the presence of myristic acid, oleic acid, palmitic acid, stearic acid, and linoleic acid (all at $125 \mu \mathrm{M}$ ), measured over $24 \mathrm{hr}$. AFU, arbitrary fluorescent units. The results are mean values of eight individual samples from one representative run. The assay was repeated three times as independent experiments, all with the same result.

amount of intracellular amyloid was found (data not shown). Intracellular amyloid was not reported to occur after 2 days in culture. Within this short time of cultivation, no extracellular amyloid deposits were seen.

\section{Discussion}

Overexpression of IAPP with an amyloidogenic amino acid sequence has been considered to be the major factor in human islet amyloidogenesis, but the absence of islet amyloid in several transgenic mouse strains with very high IAPP production have contradicted this suggestion. Therefore, additional factors need to be considered. Because, in transgenic mouse models, islet amyloid occurred after prolonged intake of a high-fat diet $(15,22)$ we found it logical to study the effects of FFAs on IAPP fibril formation. The results of this study suggest that FFAs can act as direct potent stimulators of IAPP fibrillogenesis. Amyloidogenesis includes a nucleation phase (lag phase) and a fibrillogenic phase (32). In our in vitro model with synthetic hIAPP, all tested FFAs enhanced fibril assembly by shortening of the lag phase. They also increased the Th $T$ signal. A large group of individuals with type 2 diabetes are obese and they have increased levels of plasma FFA. FFAs potentiate glucose-induced insulin release in vitro (33). It is 


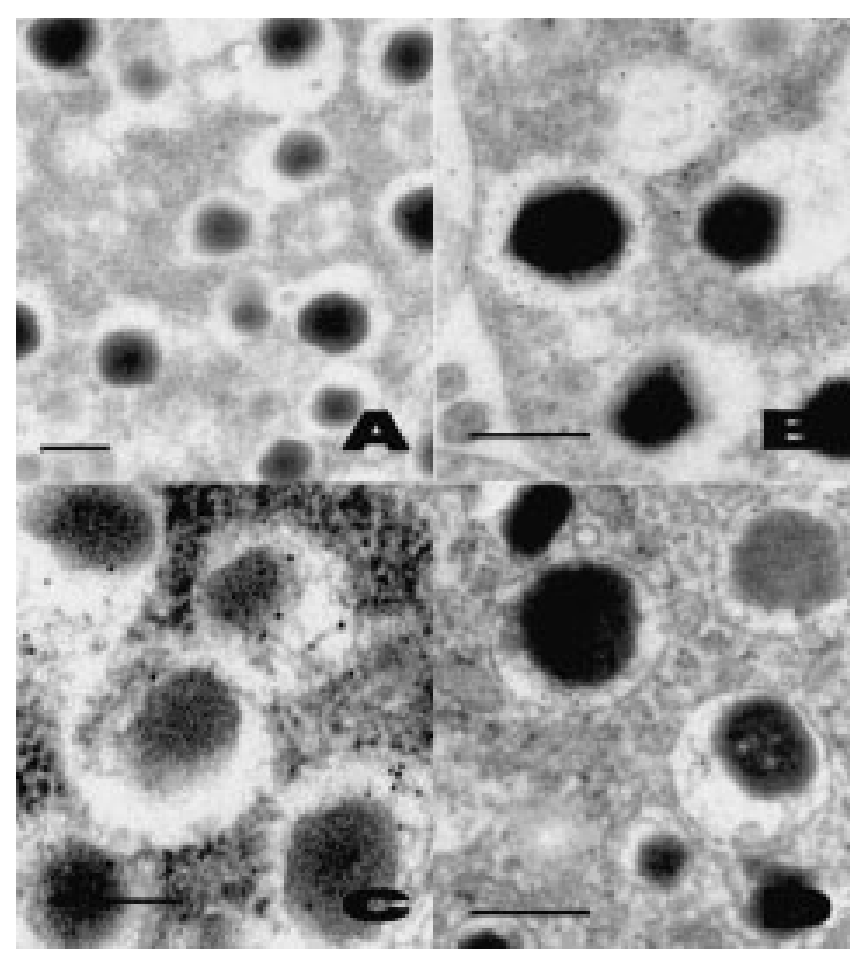

Fig. 3. Electron microscope pictures of $\beta$ cells in isolated islets from +hIAPP-mIAPP transgenic mice cultured for 2 days. (A, B) Parts of $\beta$ cells of islets cultured in the presence of $150 \mu \mathrm{M}$ albumin. No aggregate is seen in the halo region of the granules. (C) Part of $\beta$ cell of islet incubated in the presence of $300 \mu \mathrm{M}$ myristic acid and $150 \mu \mathrm{M}$ albumin. A fibrillar aggregate is present in the halo region of the $\beta$ cell. (D) $\beta$ cell granules from an islet cultured in the presence of $300 \mu \mathrm{M}$ oleic acid and $150 \mu \mathrm{M}$ albumin reveal fibrillar aggregates in the halo region of the secretory granules. In $\mathrm{B}, \mathrm{C}$, and $\mathrm{D}$ immunolabeling was performed with an IAPP-specific antiserum. Bar $=300 \mathrm{~nm}$.

possible that the combination of insulin resistance, leading to a chronic overproduction of IAPP, and effects of FFAs result in aggregation of IAPP to amyloid fibrils and thereby to a progressive $\beta$ cell loss.

In the circulation, the majority of FFAs are transported bound to albumin, and only a minor fraction is free (34). We studied the effects of FFAs bound to albumin but also without albumin. FFAs in both these states enhanced fibril formation. The mechanism(s) by which FFAs enhance fibril formation are obscure, however. A micelle formation of the FFAs would increase the concentration of hIAPP and induce fibrillogenesis. However, because the sodium salts of the FFAs were used at $\mathrm{pH} 7.4$ and the enhancement of fibril formation occurred in the presence of albumin, this explanation is highly unlikely. The electron microscope study showed that the fibrils formed in the presence of FFAs revealed the same appearance as fibrils formed without FFAs. They also bound the amyloid-specific dye Congo red and showed the typical green birefringence in polarized light. Mass spectrometric study on IAPP fibrils assembled in the presence of FFAs indicated that FFAs were not incorporated in the fibrils (G.T. Westermark, unpublished result). They therefore may have a role in nucleation and perhaps act as pathologic chaperones (35).

We have previously shown that isolated pancreatic islets from hIAPP transgenic mice develop IAPP amyloid deposits when cultivated in vitro for 10 days (22). In the present study, presence of FFAs not only enhanced fibril formation from synthetic hIAPP in vitro, but rapidly also led to the appearance of an abnormal intragranular material in $\beta$ cells of cultivated hIAPP transgenic mouse islets. This fibrillar material, which was immunoreactive for IAPP, had the same dimensions as amyloid fibrils and may be the starting point for islet amyloid. Similar structures have been reported from other hIAPP transgenic mouse strains $(14,36,37)$. Islet amyloid is mainly deposited extracellularly (38), but there is evidence that the very first amyloid may appear intracellularly $(39,40)$ and the present findings may indicate that this occurs first within the secretory vesicles. It is possible that such minute amyloid is released with secretory granules to the extracellular space and there acts as nidus for further fibril formation. Given the very short time the islets were cultivated, extracellular deposits were not expected to occur.

\section{Acknowledgments}

Supported by the Swedish Medical Research Council (project No 14040), the Research Fund of the Swedish Diabetes Association, the Novo Nordisk Foundation, Ollie and Elof Ericssons research fund, the Åke Wibergs research fund, and Stiftelsen Gamla Tjänarinnor.

\section{References}

1. Bell ET. (1952) Hyalinization of the islets of Langerhans in diabetes mellitus. Diabetes 1: 341-344.

2. Westermark P. (1995) Islet amyloid polypeptide and amyloid in the islets of Langerhans. In Leslie RDG, Robbins D (eds). Diabetes: Clinical Science in Practice. Cambridge: Cambridge University Press; pp. 189-199.

3. Westermark P, Wernstedt C, Wilander E, Sletten K. (1986) A novel peptide in the calcitonin gene related peptide family as an amyloid fibril protein in the endocrine pancreas. Biochem. Biophys. Res. Commun. 140: 827-831.

4. Westermark P, Wernstedt C, Wilander E, et al. (1987) Amyloid fibrils in human insulinoma and islets of Langerhans of the diabetic cat are derived from a neuropeptide-like protein also present in normal islet cells. Proc. Natl. Acad. Sci. U. S. A. 84: $3881-3885$.

5. Cooper GJ, Willis AC, Clark A, et al. (1987) Purification and characterization of a peptide from amyloid-rich pancreases of type 2 diabetic patients. Proc. Natl. Acad. Sci. U. S. A. 84: 8628-8632.

6. Kahn SE, Andrikopoulos S, Verchere CB. (1999) Islet amyloid: a long-recognized but underappreciated pathological feature of type 2 diabetes. Diabetes 48: 241-253.

7. Höppener JW, Ahren B, Lips CJ. (2000) Islet amyloid and type 2 diabetes mellitus. N. Engl. J. Med. 10: 411-419.

8. Gebre-Medhin S, Mulder H, Pekny M, et al. (1998) Increased insulin secretion and glucose tolerance in mice lacking islet amyloid polypeptide (amylin). Biochem. Biophys. Res. Commun. 250: 271-277. 
9. O'Brien TD, Wagner JD, Litwak KN, et al. (1996) Islet amyloid and islet amyloid polypeptide in cynomolgus macaques (Macaca fascicularis): an animal model of human non-insulindependent diabetes mellitus. Vet. Pathol. 33: 479-485.

10. Betsholtz C, Svensson V, Rorsman F, et al. (1989) Islet amyloid polypeptide (IAPP):CDNA cloning and identification of an amyloidogenic region associated with the species-specific occurrence of age-related diabetes mellitus. Exp. Cell Res. 183: 484-493.

11. D'Alessio DA, Verchere CB, Kahn SE, et al. (1994) Pancreatic expression and secretion of human islet amyloid polypeptide in a transgenic mouse. Diabetes 43: 1457-1461.

12. De Koning EJ, Höppener JW, Oosterwijk C, et al. (1993) Localisation of islet amyloid polypeptide (IAPP) in pancreatic islets of transgenic mice expressing the human or rat IAPP gene. Biochem. Soc. Trans. 21: $26 \mathrm{~S}$

13. Fox N, Schrementi J, Nishi M, et al. (1993) Human islet amyloid polypeptide transgenic mice as a model of non-insulindependent diabetes mellitus (NIDDM). FEBS Lett. 323: 40-44.

14. Yagui K, Yamaguchi T, Kanatsuka A, et al. (1995) Formation of islet amyloid fibrils in beta-secretory granules of transgenic mice expressing human islet amyloid polypeptide/amylin. Eur. J. Endocrinol. 132: 487-496.

15 . Verchere CB, D'Alessio DA, Palmiter RD, et al. (1996) Islet amyloid formation associated with hyperglycemia in transgenic mice with pancreatic beta cell expression of human islet amyloid polypeptide. Proc. Natl. Acad. Sci. U.S.A. 93: 34923496.

16. Janson J, Soeller WC, Roche PC, et al. (1996) Spontaneous diabetes mellitus in transgenic mice expressing human islet amyloid polypeptide. Proc. Natl. Acad. Sci. U.S.A. 93: 72837288.

17. Tsunehara CH, Leonetti DL, Fujimoto WY. (1990) Diet of second-generation Japanese-American men with and without non-insulin-dependent diabetes. Am. J. Clin. Nutr. 52: 731-738.

18. Lee SK, Opara EC, Surwit RS, et al. (1998) Defective glucosestimulated insulin release from perifused islets of C57BL/6J mice. Pancreas 11: 206-211.

19. Skelly RH, Bollheimer LC, Wicksteed BL, et al. (1998) A distinct difference in the metabolic stimulus-response coupling pathways for regulating proinsulin biosynthesis and insulin secretion that lies at the level of a requirement for fatty acyl moieties. Biochem. J. 331: 553-561.

20. Zhou Y-P, Grill VE. (1994) Long-term exposure of rat pancreatic islets to fatty acids inhibits glucose-induced insulin secretion and biosynthesis through a glucose fatty acid cycle. $J$. Clin. Invest. 93: 870-876.

21. Furukawa H, Carroll RJ, Swift HH, Steiner DF. (1999) Longterm elevation of free fatty acids leads to delayed processing of proinsulin and prohormone convertases 2 and 3 in the pancreatic beta-cell line MIN6. Diabetes 48: 1395-1401.

22. Westermark GT, Gebre-Medhin S, Steiner DF, Westermark P. (2000) Islet amyloid development in a mouse strain lacking endogenous islet amyloid polypeptide (IAPP) but expressing human IAPP. Mol. Med. 6: 998-1007.
23. Westermark GT, Leckström A, Ma Z, Westermark P. (1998) Increased release of IAPP in response to long-term high fat intake in mice. Horm. Metab. Res. 30: 256-258.

24. Westermark P, Li ZC, Westermark GT, et al. (1996) Effects of beta cell granule components on human islet amyloid polypeptide fibril formation. FEBS Lett. 379: 203-206.

25. Janciauskiene S, Eriksson S, Carlemalm E, Ahrén B. (1997) B cell granule peptides affect human islet amyloid polypeptide (IAPP) fibril formation in vitro. Biochem. Biophys. Res. Commun. 236: $580-585$.

26. Kudva YC, Mueske C, Butler PC, Eberhardt NL. (1998) A novel assay in vitro of human islet amyloid polypeptide amyloidogenesis and effects of insulin secretory vesicle peptides on amyloid formation. Biochem. J. 331: 809-813.

27. Wilson DM, Binder LI. (1997) Free fatty acids stimulate the polymerization of tau and amyloid beta peptides. In vitro evidence for a common effector of pathogenesis in Alzheimer's disease. Am. J. Pathol. 150: 2181-2195.

28. Puchtler H, Sweat F, Levine M. (1962) On the binding of Congo red by amyloid. J. Histochem. Cytochem. 10: 355-364.

29. LeVine H 3rd. (1993) Thioflavine T interaction with synthetic Alzheimer's disease $\beta$-amyloid peptides: detection of amyloid aggregation in solution. Protein Sci. 2: 404-410.

30. LeVine H 3rd. (1999) Quantification of beta-sheet amyloid fibril structures with thioflavin T. Meth. Enzymol. 309: 274-284.

31. Christmanson L, Betsholtz C, Leckström A, et al. (1993) Islet amyloid polypeptide in the rabbit and European hare: studies on its relationship to amyloidogenesis. Diabetologia 36: 183- 188.

32. Rochet JC, Lansbury PT Jr. (2000) Amyloid fibrillogenesis: themes and variations. Curr. Opin. Struct. Biol. 10: 60-68.

33. Prentki M, Vischer S, Glennon MC, et al. (1992) MalonylCoA and long chain acyl-CoA esters as metabolic coupling factors in nutrient-induced insulin secretion. J. Biol. Chem. 267: $5802-5810$.

34. Brodersen R, Andersen S, Vorum H, et al. (1990) Multiple fatty acid binding to albumin in human blood plasma. Eur. $J$. Biochem. 30: 343-349.

35. Wisniewski T, Frangione B. (1992) Apolipoprotein E: a pathological chaperone protein in patients with cerebral and systemic amyloid. Neurosci. Lett. 135: 235-238.

36. Couce M, Kane LA, O'Brien TD, et al. (1996) Treatment with growth hormone and dexamethasone in mice transgenic for human islet amyloid polypeptide causes islet amyloidosis and ß-cell dysfunction. Diabetes 45: 1094-1101.

37. MacArthur DL, de Koning EJ, Verbeek JS, et al. (1999) Amyloid fibril formation is progressive and correlates with beta-cell secretion in transgenic mouse isolated islets. Diabetologia 42: 12 19-1227.

38. Westermark P. (1973) Fine structure of islets of Langerhans in insular amyloidosis. Virchows Arch. A 359: 1-18.

39. O'Brien TD, Butler AE, Roche PC, et al. (1994) Islet amyloid polypeptide in human insulinomas. Evidence for intracellular amyloidogenesis. Diabetes 43: 329-336.

40. Westermark P, Eizirik DL, Pipeleers DG, et al. (1995) Rapid deposition of amyloid in human islets transplanted into nude mice. Diabetologia 38: 543-549. 